\title{
ULTRASONOGRAPHIC DETECTION OF ABDOMINAL ABSCESS IN TWO GUINEA PIGS
}

\author{
A. BEREGI ${ }^{1 *}$, Suzanne ZORN ${ }^{2 * *}$, V. MOLNÁR ${ }^{1}$ and F. BíRÓ ${ }^{1}$ \\ ${ }^{1}$ Outpatient Clinic, Department and Clinic of Internal Medicine, Faculty of Veterinary \\ Science, Szent István University, H-1400 Budapest, P.O. Box 2, Hungary; \\ ${ }^{2}$ Veterinary Practice Dr. Brückelmann + Dr. Vogt, Breisach, Germany
}

(Received December 23, 1999; accepted May 3, 2000)

\begin{abstract}
Two guinea pigs (Cavia porcellus) with clinical signs of anorexia, weight loss, depression and abdominal enlargement were examined. During ultrasound examination, a fluid-filled anechogenic structure $3-4 \mathrm{~cm}$ in diameter, with echogenic spots and a highly echogenic thick wall, was found in the pelvic region in one case and connected to the liver in the other case. An abscess or a cyst was suspected and surgical treatment including laparotomy was performed. By histopathological examination performed after surgery, a liver abscess was diagnosed in one guinea pig and an abscess in the pelvic region in the other animal.
\end{abstract}

Key words: Guinea pig, ultrasonography, abdominal abscess

The occurrence of abdominal abscess has not been reported in the guinea pig (Cavia porcellus). Ultrasonographic diagnosis of abdominal diseases and pregnancy in small rodents has been described in several publications (Cubberly et al., 1982; Inaba and Inoue, 1985; Inaba et al., 1986; Suzuki et al., 1987; Ackerman et al., 1989; Peter et al., 1990; Kupersmith and Bauck, 1991; Miles et al., 1997). Few publications have dealt with pregnancy diagnosis (Inaba and Mori, 1986) and abdominal diseases such as adrenal gland tumours and ovarian cysts in guinea pigs (Gaschen et al., 1998; Beregi et al., 1999).

This case report describes a liver abscess (Case 1) of unknown cause and an abdominal abscess (Case 2) due to castration. The major clinical signs were anorexia, depression, weight loss and abdominal distension in both animals.

\footnotetext{
${ }^{*}$ E-mail: aberegi@univet.hu; Fax: +36 (1) 4784137

${ }^{* *}$ At the time of processing these cases, Suzanne Zorn was preparing her thesis at the Students' Scientific Study Club at the University of Veterinary Science, Budapest
} 


\section{Materials, methods and results}

\section{Clinical examination}

Two male guinea pigs ( 2 and 3 years old and weighing 652 and $721 \mathrm{~g}$, respectively) were presented to our clinic for examination. The animals were suspected to have an abdominal mass based on abdominal distension and on palpatory findings (abdominal pain, rounded shape and firm structure) next to the xyphoid in Case 1 and in the pelvic region in Case 2. Both animals showed anorexia, depression and weight loss.

The abdominal mass in the pelvic region (Case 2) was detected after the owner mentioned that the animal had been castrated a half year before. In the other case (Case 1) no prior problems had occurred.

\section{Radiography}

Ventrodorsal plain radiographs of the abdomen were obtained with the guinea pigs in dorsal recumbency without anaesthesia. In both cases there was a large mass of soft tissue opacity next to the liver and in the pelvic region. Figure 1 represents the ventrodorsal radiographic image of the abscess close to the urinary bladder (Case 2). No other abnormalities were detected.

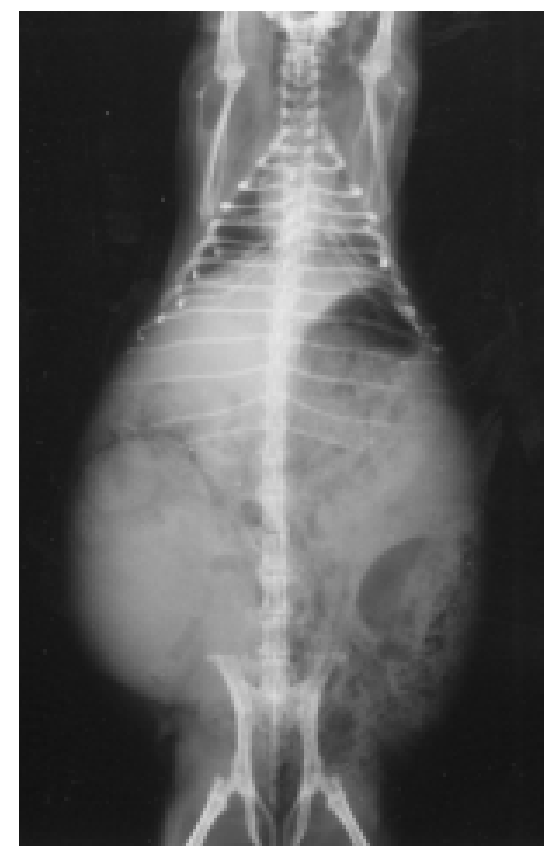

Fig. 1. Ventrodorsal radiograph of a guinea pig. Large mass of soft tissue opacity in the pelvic region (Case 2) 


\section{Ultrasound examination}

Real-time ultrasonographic images were obtained using a 7.5-10.5 MHz mechanical sector transducer (SIM 7000 CFM Challenge; Mitsubishi P91E video copy processor) without anaesthesia. The abdominal region was shaved and an ultrasound gel was applied. The transducer was oriented in the sagittal plane, and images were obtained on both sides of the abdomen. The ultrasound examination revealed a fluid-filled anechogenic structure (3-4 cm in diameter) with echogenic spots and a highly echogenic thick wall in the liver in Case 1 (Fig. 2) and next to the urinary bladder in Case 2 (Fig. 3). An abscess or cyst due to previous castration in Case 2 and of unknown origin in Case 1 was suspected and diagnostic laparotomy was performed.

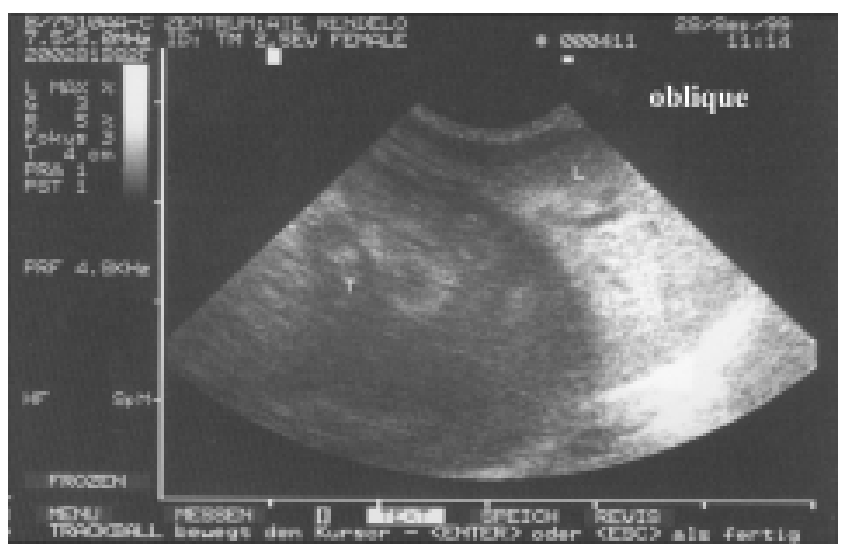

Fig. 2. Oblique abdominal ultrasonographic image of a guinea pig. Abscess (T) in the liver (L) (Case 1)

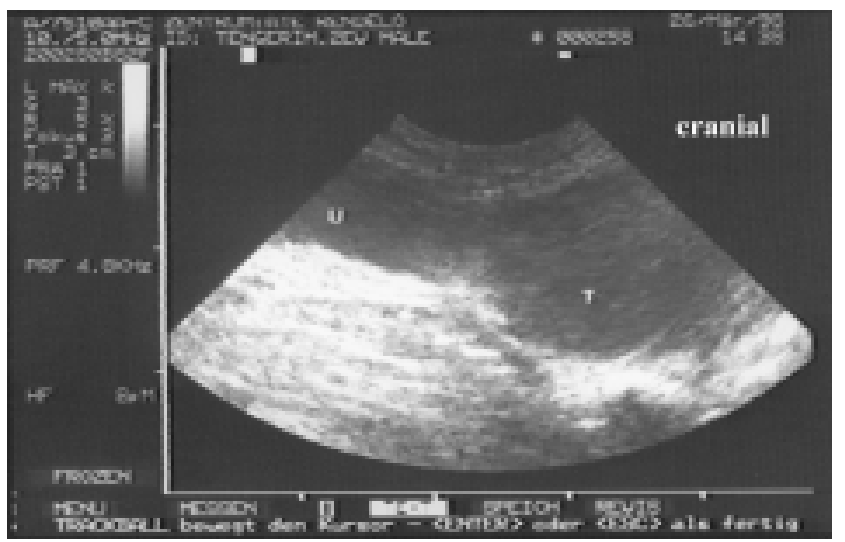

Fig. 3. Sagittal abdominal ultrasonographic image of a guinea pig. Abscess (T) close to the urinary bladder (U) (Case 2) 


\section{Surgical treatment and further examination}

The animals were anaesthetised with isoflurane before laparotomy. A median laparotomy was performed. The liver abscess (Case 1) was found to be inoperable and the animal was euthanatised (Fig. 4).

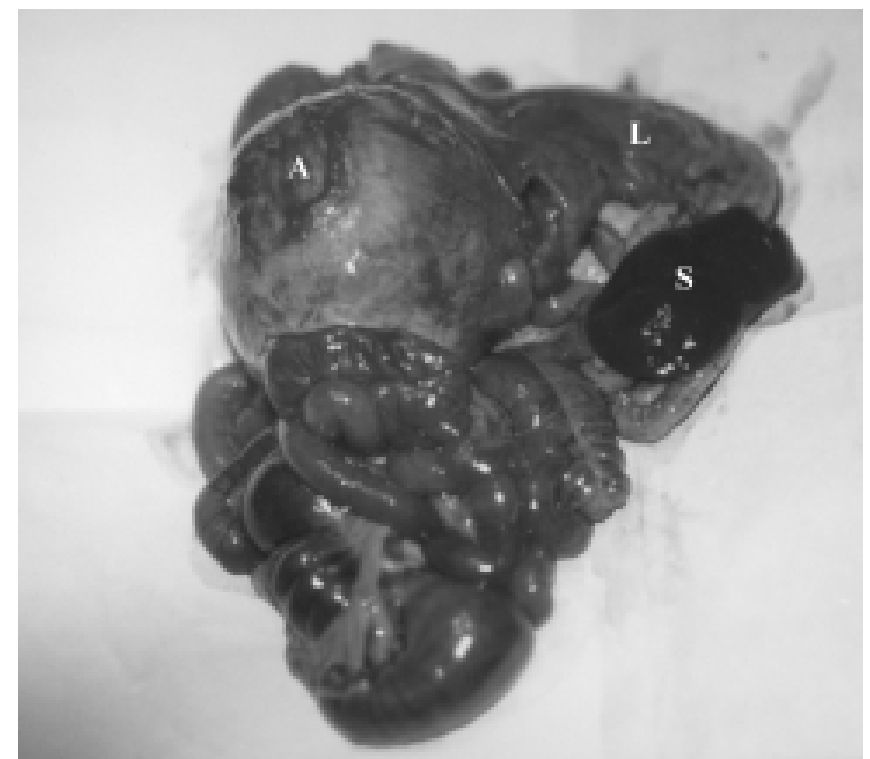

Fig. 4. Liver abscess (Case 1) in a guinea pig (post-mortem findings) (A - abscess, L - liver, S - spleen)

In Case 2, a purulent encapsulated abscess resulting from a non-absorbed ligation in the inguinal canal was extracted and then removed. The animal was treated with enrofloxacin (Ganadexil ${ }^{\circledR}$ Enrofloxacina 5\%) during the first postoperative week and the sutures were removed 10 days after surgery. Half year later this animal was examined by palpation and by abdominal ultrasonography, and no abnormal changes were found.

Both abscesses yielded Staphylococcus aureus on culture. Histopathological examination revealed that the abscesses had a thick wall, and the liver abscess was accompanied by severe liver dystrophy.

\section{Discussion}

In one of the two cases presented here (Case 2) the cause of the development of abdominal abscess is known; however, the aetiology of the liver abscess detected in the first guinea pig (Case 1) remained unknown. The clinical signs of 
anorexia, depression, weight loss and abdominal distension may indicate several diseases such as adrenal gland tumour or ovarian cyst (Konde et al., 1986; Gaschen et al., 1998; Beregi et al., 1999), but they may also occur in ascites, ovarian and abdominal tumours or hepatomegaly. Palpation and radiography are not sufficient for making a correct diagnosis.

In our clinic, ultrasonographic examination was carried out with a mechanical sector transducer of 7.5-10.5 MHz, which is suitable for examining animals of small body size. Shaving the animal's hair and using an ultrasound gel are necessary for getting high-quality images. Sedation of the animal is not required.

Both abscesses were easily distinguished from the other organs since they appeared as a fluid-filled anechogenic structure with lots of echogenic spots and a highly echogenic thick wall.

When performing castration, it is necessary to ensure sterile conditions and to use absorbable sutures, because the inguinal ring is very wide and the covered castration wounds withdraw into the abdomen through the inguinal rings.

Before surgery, abdominal ultrasonography was helpful in recognising the abdominal masses, estimating their size and location, and thus in indicating diagnostic laparotomy.

Ultrasonography is a useful tool in the examination of abdominal diseases and can be recommended as a means of diagnosing intra-abdominal diseases not only in guinea pigs but also in other small rodents.

\section{Acknowledgements}

The authors thank Miss Éva Orbán (Central Library of the Faculty of Veterinary Science, Szent István University, Budapest), Mrs Józsefné Kampó (Department and Clinic of Surgery and Ophthalmology, Faculty of Veterinary Science, Szent István University, Budapest) and Mr János Gál (Department of Pathology and Forensic Veterinary Medicine, Faculty of Veterinary Science, Szent István University, Budapest) for their help in the compilation of this paper.

\section{References}

Ackerman, N., Hager, D. A. and Kaude, J. V. (1989): Ultrasound appearance and early detection of Vx2 carcinoma in the rabbit kidney. Vet. Radiol. 30, 88-96.

Beregi, A., Zorn, S. and Felkai, F. (1999): Ultrasonic diagnosis of ovarian cyst in ten guinea pigs. Vet. Radiol. Ultrasound 40, 74-76.

Cubberly, D. A., Lee, T. G., Laughlin, C. L., Weintraub, B., Caudle, M. R. and Nielson, V. D. (1982): Importance of ultrasound determination of pregnancy in the rabbit. Am. J. Vet. Res. 43, 1802-1803. 
Gaschen, L., Ketz, C., Lang, J., Weber, U., Bacciarini, L. and Kohler, I. (1998): Ultrasonographic detection of adrenal gland tumor and ureterolithiasis in a guinea pig. Vet. Radiol. Ultrasound 39, 43-46.

Inaba, T. and Inoue, A. (1985): Use of echography in rats for pregnancy diagnosis. Jpn. J. Vet. Sci. 47, 523-525.

Inaba, T. and Mori, J. (1986): Use of echography in guinea pigs for pregnancy diagnosis. Jpn. J. Vet. Sci. 48, 615-618.

Inaba, T., Mori, J. and Tirii, R. (1986): Use of echography in rabbit for pregnancy diagnosis. Jpn. J. Vet. Sci. 48, 1003-1006

Konde, L. J., Lebel, J. L., Park, R. D. and Wrigley, R. H. (1986): Sonographic application in the diagnosis of intraabdominal abscess in the dog. Vet. Radiol. 27, 151-154.

Kupersmith, D. S. and Bauck, L. (1991): Hyperadrenocorticism in a ferret: Diagnosis (using ultrasound) and treatment. J. Small Exotic Anim. Med. 1, 66-68.

Miles, K. G., Sonea, I. M., Jackson, L. L., Riedesel, E. A., Riedesel, D. H. and Jacobson, C. D. (1997): Ultrasonographic pregnancy detection and inhalation anesthesia in the grey shorttailed opossum. Lab. Anim. Sci. 47, 280-282.

Peter, A. T., Manning, D. D. and Bosu, W. T. K. (1990): Real-time ultrasonographic determination of pregnancy and gestational age in ferrets. Lab. Anim. Sci. 40, 91-92.

Suzuki, K., Hashimoto, S., Imamichi, T., Uchino, T. and Motoyoshi, S. (1987): Differential diagnosis of hydronephrosis types I and II in rats by echography. Jpn. J. Vet. Sci. 49, 543-546. 